\title{
Efek Model Tumpangsari dan Pengaturan Barisan Jagung terhadap Evaluasi Keuntungan Hasil Jagung dan Kacang Nasi Kultivar Lokal Timor dalam Tumpangsari
}

\section{Syprianus Ceunfin ${ }^{\mathrm{a}}$}

${ }^{a}$ Fakultas Pertanian, Universitas Timor, Kefamenanu, TTU - NTT, Indonesia.

\section{Article Info}

\section{Article history:}

Received 8 Februari 2018

Received in revised form 19 Maret 2018 Accepted 4 April 2018

Keywords:

Model Tumpangsari

Pengaturan Barisan

Zay mais L.

Vigna angularis $\mathrm{L}$

LER

Kultivar Lokal Timor

\begin{abstract}
Abstrak
Menurunnya produksi hasil pertanian saat ini menjadi salah satu tantangan bagi peneliti-peneliti pertanian karena lahan pertanian semakin sempit serta tingginya luas lahan tidur. Salah satu cara tepat meningkatkan produksi lahan dan tanaman adalah dengan memanfaatkan ruang antara tanaman baik pada tanaman semusim maupun tanaman umur panjang. Salah satu ruang yang memungkinkan untuk membudidayakan tanaman kacang nasi adalah sela antar tanaman jagung. Penelitian ini bertujuan untuk mengetahui efek model tumpangsari dan pengaturan barisan tanam jagung terhadap hasil dan evaluasi keuntungan hasil jagung dan kacang nasi kultivar loka Timor dalam sistem tumpangsari. Perlakuan dirancang dengan menggunakan Rancangan Acak Kelompok (RAK) Faktorial 3×2+kontrol dan diulang 3 kali, faktor pertama adalah model tumpang sari yang terdiri dari tiga aras yaitu tumpangsari sela; dan tumpangsari Salome (model Timor ); tumpangsari gabungan dan faktor kedua adalah pengaturan barisan tanam jagung: Single Row; Doblerow. Parameter yan diamati adalah berat biji jagung per petak (t/ha), berat biji kacang nasi per petak (t/ha), total LER, total ATER, Agresivitas tanaman, Rasio Kompetisi tanaman. Data yang dikumpulkan dianalisis menggunakan Analisis Anova Rancangan Acak Kelompok Faktorial kemudian dilanjutkan dengan uji Duncan pada taraf $\alpha 0,05$. Hasil penelitian menunjukkan bahwa terjadi interaksi terhadap berat kering biji jagung per petak, total LER, total ATER, dan rasio kompetisi jagung. Tumpangsari memberikan hasil $\geq 1$, yang berarti menguntungkan pada perlakuan model tumpangsari maupun pada pengaturan barisan tanaman.. (O2018 dipublikasikan oleh Savana Cendana.
\end{abstract}

\section{Pendahuluan}

Menurunnya produksi hasil pertanian saat ini menjadi salah satu tantangan bagi peneliti-peneliti pertanian karena lahan pertanian semakin sempit. Kendala yang dihadapi saat ini adalah lahan yang digunakan untuk mengusahakan tanaman pangan semakin sempit, kesuburan lahan yang terus menurun sebagai akibat pengelolaan lahan pertanian yang salah. Pembukaan hutan tidak direkomendasikan karena menimbulkan ketimpangan ekologi. Salah satu cara untuk meningkatkan produktivitas lahan dan untuk meningkatkan pendapatan petani di lahan yang kurang produktif adalah dengan memperbaiki kandungan bahan organik tanah, melakukan diversifikasi panen serta memperbaiki cara penutupan lahan melalui pemulsaan vegetatif (Jaya et al., 2014). Oleh karena itu peningkatan produksi tanaman pangan adalah dengan memanfaatkan ruang antara tanaman baik pada tanaman semusim maupun tanaman umur panjang. Salah satu ruang yang memungkinkan untuk membudidayakan tanaman kacang nasi (Vigna angularis L.) adalah jarak antar tanaman jagung. Tantangan yang lebih besar bagi peneliti adalah menemukan kombinasi pola tumpangsari dan cara penanaman yang benar, kepadatan tanaman dalam unit lahan yang tepat akan mempertahankan atau meningkatkan pertumbuhan dan hasil jagung maupun tanaman kacang (Nthabiseng et al., 2015).

Pulau Timor merupakan salah satu pulau di Indonesia yang memiliki curah hujan rendah. Oleh karena itu petani di pulau Timor khususnya kabupaten Timo Tengah Utara (TTU) selalu menerapkan sistem tumpangsari untuk meningkatkan ketahanan pangan keluarga. Sistem tumpangsari yang diterapkan di kabupaten TTU berbeda dengan cara yang diterapkan secara nasional. Sistem tanam in disebut tsen bola' mese' atau Salome (Levis et al., 2017). Salome adalah sistem tumpangsari antara jagung dengan beberapa spesies tanaman dalam lubang tanam yang sama pada waktu yang bersamaan.

Pertumbuhan dua tanaman dalam bidang tanam yang sama pada waktu yang bersamaan atau musim tanam yang sama menyebabkan persaingan terhadap sumberdaya atau memberikan fasilitas pertumbuhan bagi tanaman yang ditumpangsarikan (Quaye et al., 2011). Oleh karena itu kepadatan dan propors tanaman dalam tumpangsari sangat penting dalam menentukan hasil dan efisiensi produksi tanaman. Jagung yang ditanam pada baris tunggal dengan kedela memberikan hasil biji yang jauh lebih tinggi daripada yang ditanam pada barisan ganda kedelai, sedangkan kedelai yang ditanam pada barisan ganda meningkatkan hasil biji sebesar 31\% dibandingkan dengan baris tunggal (Tsay, 1985). Pengaturan baris ganda atau doble row memberikan hasil biji jagung dan hasil kacang lebih tinggi dari penataan tanaman dengan barisan tunggal pada dua musim tanam yang berbeda (Nthabiseng et al., 2015).

Menurut Mutungamiri et al. (2001), penataan ruang kacang dari dua baris kacang di antara baris jagung dan penanaman kacang-kacangan pada baris yang sama dengan jagung memberikan hasil jagung lebih rendah dari penataan baris alternatif dengan jagung. Walaupun demikian menurut Banik \& Sharma (2009); Nthabiseng et al., (2015), tumpangsari jenis tanaman jagung dan legum yang ditanam dengan dua baris legum setelah satu baris jagung memberikan respon lebih baik terhadap kedua tanaman dalam tumpangsari. Pengaturan tumpangsar kacang tanah baris tunggal yang diselingi dengan jagung baris tunggal dan kacang tanah baris tunggal yang diselingi dengan jagung baris ganda adalah yang paling menguntungkan karena nilai rasio kesetaraan lahan $\geq 1$ (Konlan et al., 2013)

Penelitian ini bertujuan untuk mengetahui efek model tumpangsari dan pengaturan barisan tanam jagung terhadap hasil dan evaluasi keuntungan hasil jagung dan kacang nasi kultivar lokal Timor dalam sistem tumpangsari.

\section{Metode}

Penelitian dilaksanakan di kebun percobaan Fakultas Pertanian Universitas Timor pada bulan Januari sampai Mei 2017 menggunakan Rancangan Acak Kelompok (RAK) Faktorial, faktor pertama adalah model tumpang sari (S) yang terdiri dari tiga aras yaitu tumpangsari sela $=\mathrm{S} 1$ ); dan tumpangsari Salome $($ model Timor $=\mathrm{S} 2)$; tumpangsari gabungan $(\mathrm{S} 2+\mathrm{S} 1=\mathrm{S} 3)$ dan faktor kedua adalah pengaturan barisan tanam jagung (J): Single row $(\mathrm{J} 1)$; Doble row $(\mathrm{J} 2)$ : Kombinas perlakuan: $S_{1} J_{1}, S_{1} J_{2}, S_{2} J_{1}, S_{2} J_{2}, S_{3} J_{1}, S_{3} J_{2}+3$ kontrol dan diulang 3 kali sehingga terdapat 27 unit perlakuan.

Luas lahan yang digunakan dalam penelitian ini adalah $44,8 \mathrm{~m}^{2}$ dengan ukuran setiap unit perlakuan 2,5 $\mathrm{m} \times 1,2 \mathrm{~m}$. Setiap blok terdiri dari 9 unit perlakuan. Benih jagung yang digunakan adalah jagung lokal Timor umur genjah, dan kacang nasi lokal Timor. Benih jagung dan kacang ditanam dengan cara ditugal dengan jarak tanam jagung $70 \mathrm{~cm} \times 20 \mathrm{~cm}$, dan jarak tanam kacang nasi $35 \mathrm{~cm} \times 20 \mathrm{~cm}$. Jumlah benih setiap lubang tanam adalah 3 biji benih jagung dan 3 biji benih kacang nasi, kemudian tanaman dikebiri menyisakan masingmasing 2 tanaman setelah berumur 14 hari. Pupuk yang digunakan dalam penelitian ini adalah pupuk guano sebanyak 8,5 t/ha dan kompos 2,5 t/ha sebagai pupuk dasar. Pemeliharaan terhadap tanaman berupa penyiraman pada saat tidak terjadi hujan, penyiangan dan penggemburan tanah, penyulaman (menggunakan tanaman yang telah dipersiapkan dalam polybag serta pengendalian hama pada saat terjadi serangan. Pemungutan hasil jagung maupun kacang nasi dilakukan pada saat tanaman menunjukkan tanda-tanda masak fisiologi seperti klobot jagung telah kering dan warna biji mengkilap, sedangkan kacang nasi dipungut setelah polong kering dan berwarna coklat.

Parameter yang diamati dalam penelitian ini adalah 1) berat biji jagung per petak ( $\mathrm{t} / \mathrm{ha}$ ) yang dihitung dengan mengkorversikan hasil tanaman per petak ke hektar; 2) berat biji kacang nasi per petak (t/ha) yang dihitung dengan mengkorversikan hasil tanaman per petak ke hektar; dan 3) evaluasi keuntungan hasil.

Evaluasi keuntungan hasil meliputi 1) Land Equivalent Ratio (LER) yang dihitung menggunakan rumus menurut Beets (1982); 2) Area Time Equivalen Ratio (ATER) yang dihitung menggunakan rumus Beets (1982); Agresivity (A) yang dihitung menggunakan rumus yang diperkenalkan oleh Palaniappan (1985) dan Ratio Competisi (RC) yang dihitung menggunakan sesuai Palaniappan, (1985).

Data yang dikumpulkan dianalisis menggunakan Analisis Anova Rancangan Acak Kelompok Faktorial kemudian dilanjutkan dengan uji Duncan pada taraf $\alpha$ 0,05 sesuai petunjuk Gomez \& Gomez, (1984) menggunakan program SAS 9.01.

\section{Hasil dan Pembahasan}

Hasil penelitian menunjukkan bahwa terjadi interaksi pada parameter pengamatan berat kering biji jagung per petak, total LER, total ATER, dan rasio kompetisi tanaman jagung sedangkan parameter lain tidak terjadi interaksi.

\subsection{Berat Kering Biji Jagung Per Petak (t/ha)}

Pengamatan terhadap berat kering biji jagung per petak menunjukkan bahwa model tumpangsari Salome dengan pengaturan barisan doble row menghasilkan berat biji paling tinggi pada tumpangsari yang berbeda nyata dengan kombinasi perlakuan model tumpangsari gabungan dengan pengaturan barisan doble row (Gambar 1.).

\subsection{Berat Kering Biji Kacang Per Petak (t/ha)}

Pengamatan terhadap berat kering biji kacang nasi menunjukkan bahwa perlakuan model tumpangsari Salome memberikan hasil paling tinggi tetapi tidak berbeda nyata dengan model tumpangsari lainnya (Gambar 2.), sedangkan pada perlakuan doble row menghasilkan berat biji tertinggi tetapi tidak berbeda nyata dengan perlakuan single row (Gambar 3.). 


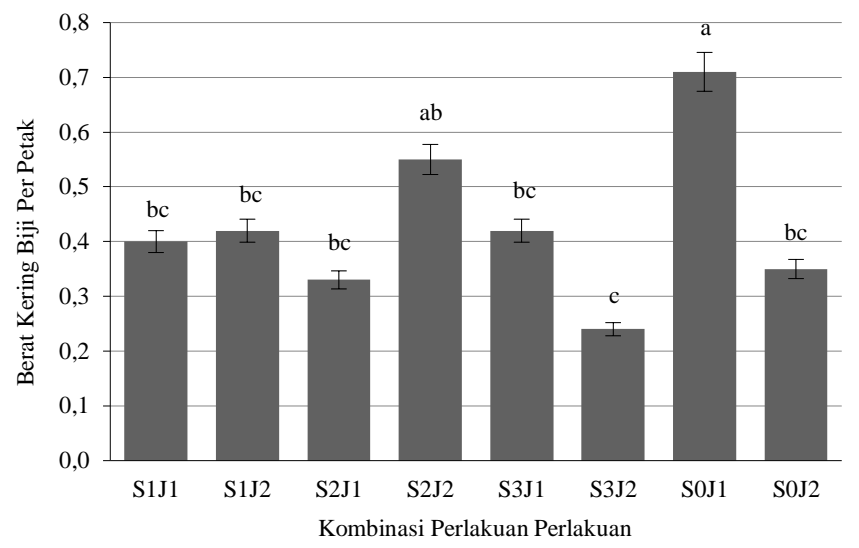

Gambar 1. Efek model tumpangsari dan pengaturan barisan terhadap berat kering biji jagung per petak (t/ha); huruf sama yang terletak di atas gambar tidak berbeda nyata pada uji taraf nyata DMRT $\alpha 0,05$.

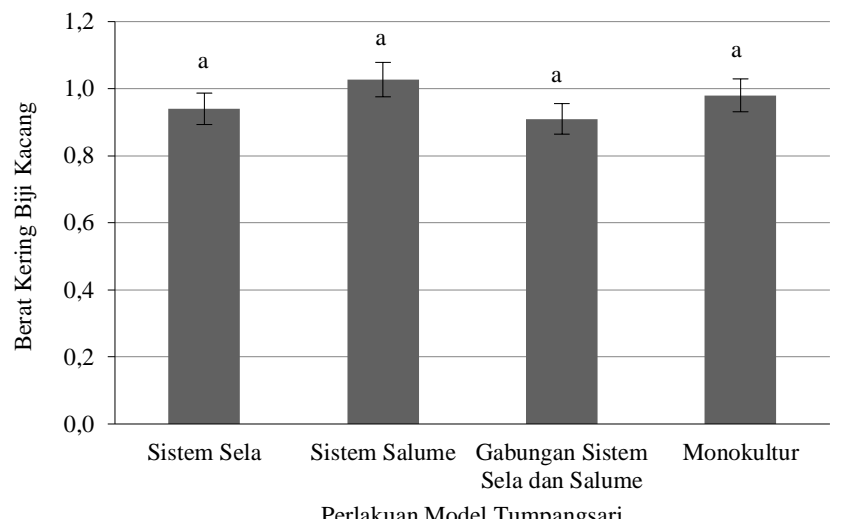

Gambar 2. Efek Model Tumpangsari Terhadap Hasil biji Kacang Nasi per Petak (t/ha); Huruf sama yang terletak di atas gambar tidak berbeda nyata pada uji taraf nyata DMRT $\alpha 0,05$.

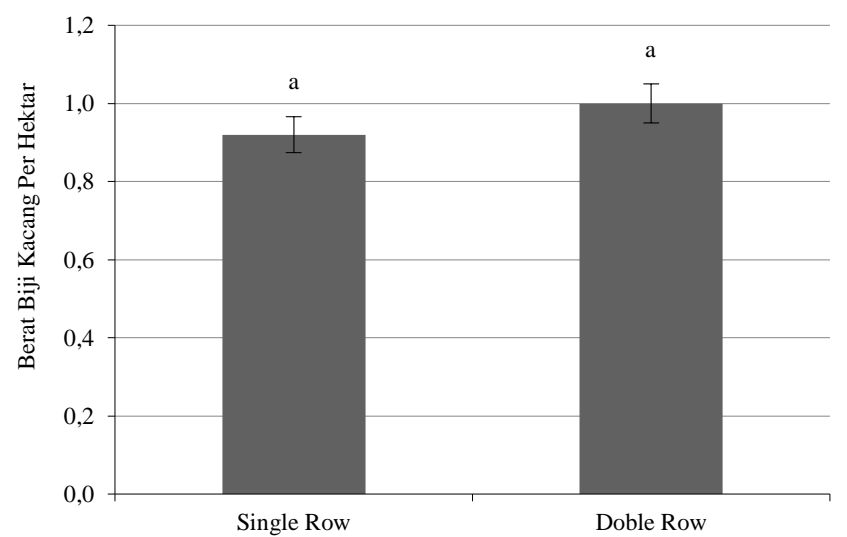

Gambar 3. Efek Pengaturan Barisan Terhadap Hasil biji Kacang Nasi per Petak; Huruf sama yang terletak di atas gambar yang sama tidak berbeda nyata pada uji taraf nyata DMRT $\alpha 0,05$.

\subsection{Evaluasi Keuntungan Hasil}

\section{a. Total Land Equivalent Ratio (LER)}

Pengamatan terhadap nilai total LER menunjukkan bahwa mode tumpangsari gabungan yang dikombinasikan dengan pengaturan barisan single row menghasilkan nilai LER paling tinggi pada tumpangsari dan berbeda nyata dengan kombinasi perlakuan model tumpangsari gabungan dengan pengaturan barisan doble row (Gambar 4.)

\section{b. Total Area Time Equivalent Ratio (ATER)}

Pengamatan terhadap nilai total ATER menunjukkan bahwa model tumpangsari gabungan yang dikombinasikan dengan pengaturan barisan single row menghasilkan nilai ATER paling tinggi pada tumpangsari dan berbeda nyata dengan kombinasi perlakuan model tumpangsari gabungan dengan pengaturan barisan doble row (Gambar 4.).

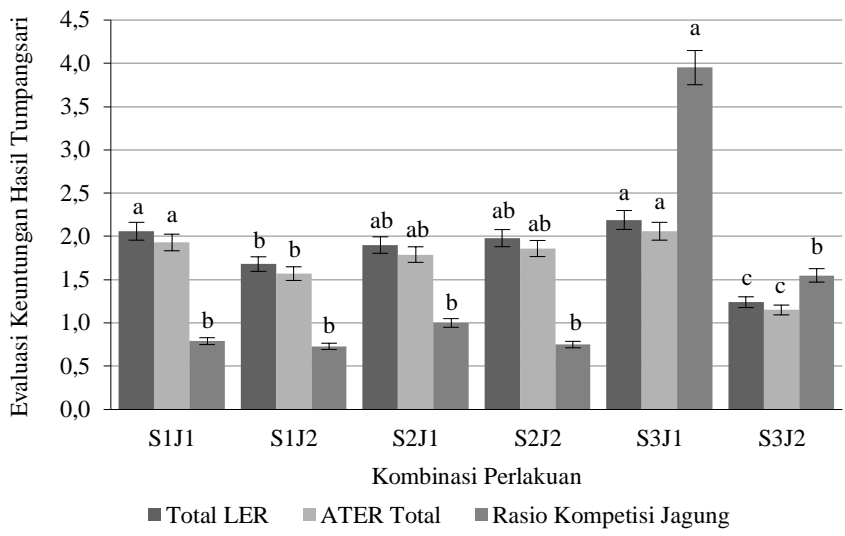

Gambar 4. Efek Model Tumpangsari dan Pengaturan Barisan Terhadap Total LER, Tota ATER, dan rasio Kompetisi; huruf sama yang terletak di atas gambar dengan warna yang sama tidak berbeda nyata pada uji taraf nyata DMRT $\alpha 0,05$.

\section{c. Agresivitas Tanaman}

Pengamatan terhadap nilai Agresivitas tanaman tidak terjadi interaksi. Agresivitas tanaman jagung menghasilkan nilai negatif dan tanaman kacang nas menghasilkan nilai agresivitas positif serta tidak berbeda nyata pada kedua jenis tanaman pada perlakuan model tumpangsari (Gambar 5.), sedangkan pada perlakuan pengaturan barisan menunjukkan bahwa barisan single row menghasilkan nilai agresivitas positif dan berbeda nyata dengan perlakuan pengaturan barisan doble row (Gambar 6.). Tanaman yang kuat dalam berkompetisi memberikan hasil optimal pada akhir siklus kehidupan.

\section{d. Rasio Kompetisi Tanaman}

Pengamatan terhadap rasio kompetisi jagung menunjukkan bahwa model tumpangsari gabungan yang dikombinasikan dengan pengaturan barisan single row menghasilkan nilai ATER paling tinggi dan berbeda nyata dengan kombinasi perlakuan lainnya (Gambar 4.), sedangkan rasio kompetisi tanaman kacang nasi tidak terjadi interaksi. Perlakuan model tumpangsari sela tidak berbeda nyata dengan model tumpangsari lainnya (Gambar 7.), sedangkan pengaturan barisan dalam tumpangsari tidak terjadi beda nyata antar aras perlakuan (Gambar 8.).

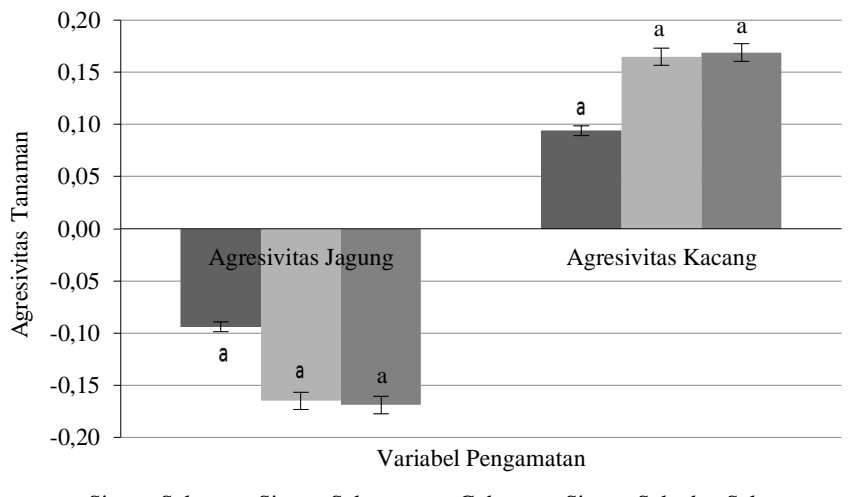

- Sistem Sela $\quad$ Sistem Salume $\quad$ Gabungan Sistem Sela dan Salume

Gambar 5. Efek Model Tumpangsari terhadap Agresivitas tanaman dalam tumpangsari; Huruf sama yang terletak di atas gambar pada kelompok yang sama tidak berbeda nyata pada uji taraf nyata DMRT $\alpha 0,05$

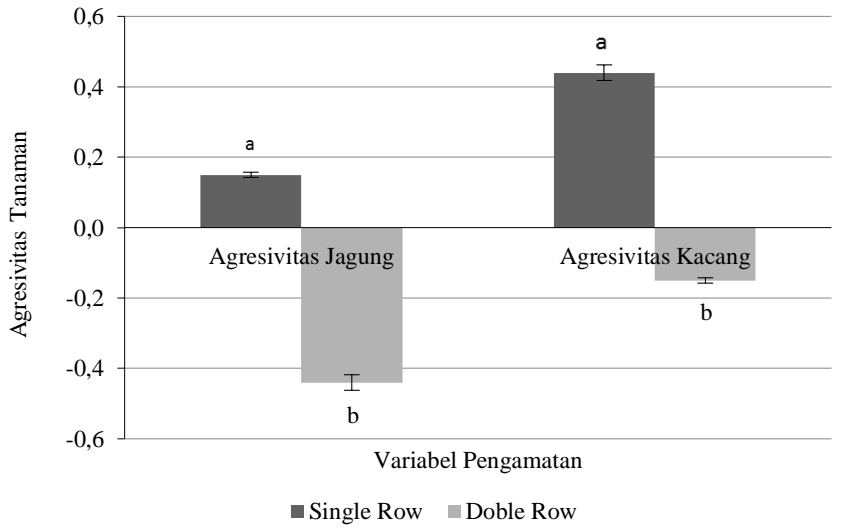

Gambar 6. Efek Pengaturan Barisan terhadap Agresivitas tanaman dalam tumpangsari; Huruf sama yang terletak di atas gambar pada kelompok yang sama tidak berbeda nyata pada uji taraf nyata DMRT $\alpha 0,05$. 


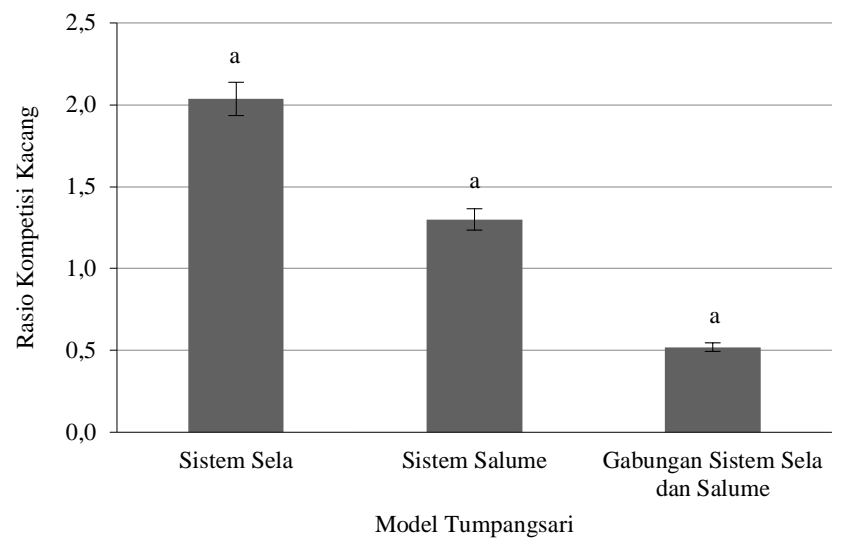

Gambar 7. Efek model tumpangsari terhadap rasio kompetisi tanaman kacang nasi dalam tumpangsari; Huruf sama yang terletak di atas gambar yang sama tidak berbeda nyata pada uji taraf nyata DMRT $\alpha 0,05$.

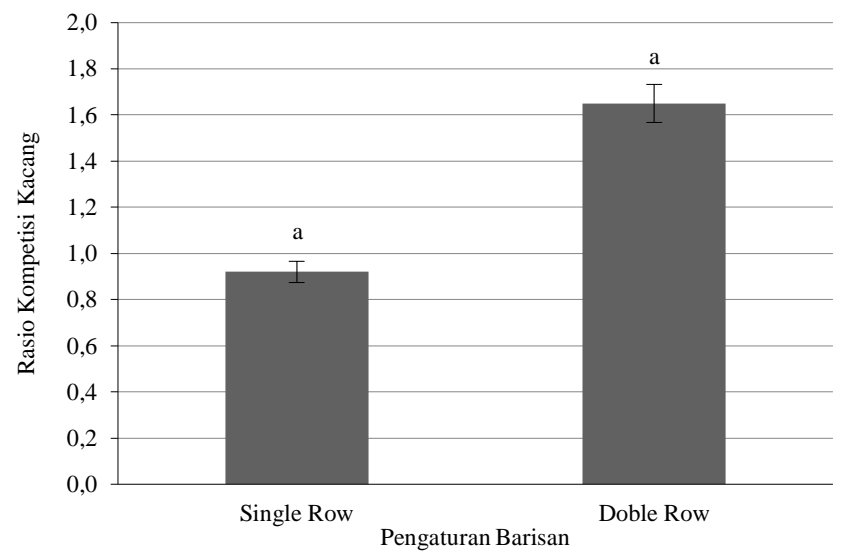

Gambar 8. Efek model tumpangsari terhadap rasio kompetisi tanaman kacang nasi dalam tumpangsari; Huruf sama yang terletak di atas gambar tidak berbeda nyata pada uji taraf nyata DMRT $\alpha 0,05$.

\subsection{Pembahasan}

Hasil penelitian menunjukkan bahwa hasil tanaman jagung dalam tumpangsari sangat rendah yang disebabkan oleh rendahnya agresivitas tanaman jagung pada semua model tumpangsari sedangkan pada pengaturan barisan doble row agresivitas tanaman rendah dalam memperoleh sumberdaya baik sumberdaya di atas tanah maupun sumberdaya di dalam tanah, namun tetap kompetitif untuk menghasilkan biji. Selain itu rendahnya hasil tanaman jagung dalam tumpangsari juga disebabkan oleh tajuk tanaman kacang nasi yang relatif lebar, merambat dan melilit tanaman jagung sehingga perkembangan tanaman jagung menjadi terhambat. Hal ini diperkuat oleh pernyataan Palaniappan (1985) bahwa jika nilai Agresivitas $(\mathrm{A})=0$ berarti tanaman sama-sama kompetitif, $\mathrm{A}=$ + (positif) tanaman lebih dominan dalam berkompetisi, $\mathrm{A}=$ - (negatif) tanaman kalah dalam berkompetisi. Hasil tanaman kacang nasi dalam tumpangsari cukup tinggi karena agresivitas tanaman kacang dalam mendapatkan sumberdaya sangat tinggi.

Tumpangsari tanaman jagung dan kacang nasi menghasilkan nilai LER dan ATER $>1$ hal ini berarti model tumpangsari yang dikombinasikan dengan pengaturan barisan tanaman sangat cocok dan layak untuk diterapkan dalam sistem pertanaman karena sangat menguntungkan. Hal ini senada dengan pernyataan Ceunfin et al., (2017), bahwa nilai LER dan ATER > 1 menggambarkan sistem tanaman monokultur memerlukan lahan yang lebih luas dibandingkan dengan pola tumpangsari.

\section{Simpulan}

Terjadi interaksi antara model tumpangsari dan pengaturan barisan terhadap hasil berat kering biji jagung per petak, total LER, total ATER dan rasio kompetisi jagung. Kombinasi perlakuan model tumpangsari Salome dengan pengaturan barisan doble row menghasilkan berat kering biji jagung tertinggi. Berat biji kacang nasi paling baik dihasilkan oleh perlakuan tumpangsari Salome pada perlakuan model tumpangsari sedangkan pada perlakuan pengaturan barisan berat biji kacang dihasilkan oleh perlakuan doble row. Kombinasi antara model tumpangsari dan pengaturan barisan menghasilkan nilai LER dan ATER $>1$ yang berarti menguntungkan.

\section{Pustaka}

Banik, P. \& Sharma, R.C. 2009. Yield and resource utilization efficiency in baby corn-legume intercropping system in the eastern plateau of India. Journal of Sustainable Agriculture 33: 379- 305.

Beets W.C., 1982. Multiple Cropping and Tropical Farming System. Chicago: Gower Publ Co. Chicago.
Ceunfin, S., Prajitno, D., Suryanto, P. \& Putra, E.T.S. 2017. Penilaian Kompetisi dan Keuntungan Hasil Tumpangsari Jagung Kedelai di Bawah Tegakan Kayu Putih. Savana Cendana, 2(01): 1-3.

Gomez, K.A. \& Gomez, A.A. 1984. Statistical Procedures for Agricultural Research. New York: John Wiley \& Sons.

Hernita, D. 2001. Kajian Ragam Tumpangsari Antara Labu Kuning dan Jagung. Yogyakarta: Fakultas Pertanian Universitas Gadjah Mada,

Jaya, I.K.D., Nurrachman, \& Jayaputra. 2014. The potential of intercropping food crops and energy crop to improve productivity of a degraded agriculture land in arid tropics. Journal Of Degraded Andmining lands management 1(03): 111-116.

Konlan, S., Sarkodie-Addo, J., Kombiok, M.J., Asare, E. \& Bawah. 2013. Yield Response Of Three Groundnut (Arachis hypogaea L.) Varieties Intercropped With Maize (Zea mays) In The Guinea Savanna Zone of Ghana. Academic Journals. 6(32): 76-84.

Levis, L. R., K. Sukesi, Sugiyanto \& Y. Yuliati. 2017. Farmers Behaviour Regarding Food Security By Practicing The 'Salome' Farming System As Local Wisdom In West Timor, East Nusa Tenggara Province, Indonesia. Tropical and Subtropical Agroecosystems, 20(2017): 231 - 236.

Mutungamiri, A., I.K. Mariga., \& O.A. Civinge. 2001. Evaluation of maize (Sea mayz L.) cultivars and density for dryland maize bean intercropping. Trop.agric. 78: 8-12.

Nthabiseng, T. R., K. Mariga Irvine. \& P. Mabapa Moshibudi. 2015. Response of a Maize Or Dry Bean Intercrop To Maize Density And Dry Bean Arrangement Under Rainfed Conditions. International Journal of Agronomy and Agricultural Research (IJAAR). 6(06):18-29.

Palaniappan. 1985. Cropping system in the Tropic: Prinsiples and Management. Coimbataro: Wiley Eastern Limited and Tamil Nadu Agricultural University.

Tsay, J. 1985. Physiological studies of cassava-soybean intercropping. Australia: Univ. of Queensland. Australia.

Quaye, A. A. Addo., A.A. Darkwa \& G. K. Ocloo. 2011. Yield And Productivity Of Component Crops In A Maize- Soybean Intercropping System As Affected By Time Of Planting And Spatial Arrangement. Journal of Agricultural and Biological Science (C2006-2011 Asian Research Publishing Network (ARPN). 6(09).

Yilmaz, F., M. Atak, \& M. Erayman. 2008. Identification of Advantages of Maize-Legume Intercropping over Solitary Cropping through Competition Indices in the East Mediterranean Region.Turk J. Agric 32: 111-119. 